Article

\title{
A Practical Load-Source Coordinative Method for Further Reducing Curtailed Wind Power in China with Energy-Intensive Loads
}

\author{
Dandan Zhu ${ }^{1, *}$, Wenying Liu ${ }^{1}$, Yang $\mathrm{Hu}^{1}$ and Weizhou Wang ${ }^{2}$ \\ 1 State Key Laboratory of Alternate Electrical Power System with Renewable Energy Sources, North China \\ Electric Power University, Beijing 102206, China; liuwenyingls@sina.com (W.L.); \\ hyangsunshine@126.com (Y.H.) \\ 2 State Grid Corporation of Gansu Province, Lanzhou 730000, China; wangweizhou945@sina.com \\ * Correspondence: zhudadnan0915@ncepu.edu.cn; Tel.: +86-156-5291-2949
}

Received: 6 September 2018; Accepted: 23 October 2018; Published: 26 October 2018

\begin{abstract}
Large-scale wind power farms in China are suffering from large amounts of curtailed wind power in the conventional dispatching mode. Energy-intensive loads have great potential in providing service regulation to help consume the curtailed wind power. However, constrained by technical limitations, the regulating power of energy-intensive loads cannot fully follow the fluctuating wind power. This would result in insufficient utilization of the regulation capability of energy-intensive loads, which limits the promotion in consumption of curtailed wind power brought by load-source coordination. With this concern, a brand new method for further consuming the curtailed wind power, which involves using coal-fueled units to provide ancillary regulation for the coordination of energy-intensive loads and wind power is presented, and a corresponding bi-level coordinative model is also established. The first level of optimization is intended to maximize the consumption of curtailed wind power with minimum ancillary regulation energy. The second level of optimization is to allocate the ancillary regulating power with minimum regulation cost. Wind power consumption was increased by 3,369.25 MWh and utilization rate of energy-intensive loads was promoted to $100 \%$ in the case analysis, which verifies the effectiveness of the proposed method.
\end{abstract}

Keywords: load-source coordination; energy-intensive load; wind power consumption; ancillary regulation; utilization promotion

\section{Introduction}

\subsection{Background and Motivation}

It is reported that the installed wind power capacity in China had reached $163.67 \mathrm{GW}$ by the end of 2017 [1], however the lack of regulation capacity in the power system severely limits the consumption of wind power, especially in those districts where large-scale wind power farms are located. In 2017 the rates of curtailed wind power in Gansu, Xinjiang and Jilin were 33\%, 29\% and 21\%, respectively [1]. Wind power curtailment occurs in cases where wind generation is more than the load minus must-run generation [2]. The excess of wind energy needs to be curtailed to keep the balance between demand and supply [2]. That is to say, no downward regulation can be provided by the units in the system when there is curtailed wind power, which is also the premise of this paper. Therefore promoting wind power consumption requires additional regulating services [3]. Meanwhile, in China energy-intensive loads are often built in the same districts where large scale wind power systems are located. The coincidence of the distribution of energy-intensive loads and wind power farms in China 
provides great opportunities for increasing the wind power consumption with the regulation ability of energy-intensive loads.

The basic design of the load-source coordination to additionally reduce the curtailed wind power is to increase the load power when there is wind curtailment. Considering the regulation limitations of the energy-intensive loads, for example the stable operation period required after one regulation, the regulating load power cannot fully follow the fluctuating wind power. This is what the term characteristic mismatches used in this paper means. The characteristic mismatches would inevitably result in insufficient utilization of energy-intensive loads potential in reducing the curtailed wind power (detailed discussion is provided in Section 3.1). How to make the best use of the regulating capability of the energy-intensive loads to reduce the wind power curtailment under the characteristic mismatches and the corresponding scheduling model are of great significance for further promoting wind power consumption.

\subsection{Literature Review}

Energy-intensive loads are promising flexible service providers and they can be better organized in the load-source coordination than other types of loads [4], say, residential loads, as the energy-intensive loads often feature huge capacity and centralized control modes. Pelzer stressed the significance of involving the bi-directional regulation ability of energy-intensive loads in the demand side response and made prospects for the application [5]. Many studies have explored the regulation possibility of various energy-intensive loads. The aluminum smelting load was regarded as an ideal supplier of regulation based on researches on its capability of providing regulating services [6]. The cement industry load was modeled as a shifting load to reduce the operating cost of the enterprise [7]. Wood industry loads were also believed to be qualified potential regulating service suppliers based on a case analysis [8]. The regulation capability of metal casting industry loads in participating in the ancillary market was studied too [9]. These studies verified the flexibility of energy-intensive loads and laid a technical foundation for exploiting energy-intensive loads' regulating capability to consume the curtailed wind power.

Besides, electrical energy is usually one of the largest component costs in energy-intensive enterprises, for example, in aluminum production it accounts for 30 to $40 \%$ [6]. If the tariff of curtailed wind power is discounted, it would contribute a lot to lowering the production cost and providing more benefits for energy-intensive enterprises, which would in turn interest the enterprises to take part in the regulation for consuming the curtailed wind power.

For the control of energy-intensive loads, most studies [3,7,10-16] are focused on exploiting the regulation capability of energy-intensive loads in load shedding and shifting for peak load management and the operation cost reduction of energy-intensive enterprises. Only a few have investigated the coordination of energy-intensive loads and wind power. Bao [17] and $\mathrm{Xu}$ [18] employed energy-intensive loads to support the frequency control of power system integrated with wind power. Liao [19] proposed a direct control scheme of energy-intensive loads to smooth the wind power fluctuation, but the wind power consumption is not the research emphasis in the mentioned literatures. Chen [20] designed a decomposed coordinative scheduling approach to organize the coordination between energy-intensive enterprises and the power system with wind power integrated, thus to promote the consumption of wind power and bring the enterprises more benefit. However, a minimum steady operation duration required by some energy-intensive loads is not considered. To sum up, flexibility of energy-intensive loads has been applied in improving the performance of power system in many ways, however, most of the studies have focused on peak load management and frequency control, and practical load-source coordinative method of consuming the curtailed wind power with energy-intensive loads remains an important issue to be addressed. 


\subsection{Contributions}

This paper discusses how to make full use of the flexibility of energy-intensive loads to consume the curtailed wind power considering technical requirements of energy-intensive loads. Based on a real project in Western China, many application limitations are considered in this paper to make the proposed method practical. And as the ancillary service market is not fully developed yet in China, the mode of direct load control [21] is adopted. The main contributions of this paper can be summarized as follows:

(1) Ancillary regulation from the coal-fueled units is involved to alleviate the characteristic mismatches between energy-intensive loads and wind power, which helps further promote the wind power consumption with energy-intensive loads.

(2) A coordinative model is given, which takes both the technical requirements of energy-intensive loads and ancillary generation cost into consideration.

The remainder of this paper is organized as follows: in Section 2, characteristics of energy-intensive loads and wind power are introduced. The insufficient utilization of regulation capacity of energy-intensive loads resulting from characteristic mismatches between energy-intensive loads and wind power is analyzed in Section 3, along with the proposal of ancillary regulating of coal-fueled units. A bi-level coordinative model to promote wind power consumption with energy-intensive loads' flexibility considering the ancillary regulating provided by coal-fueled units is constructed in Section 4 . A case analysis is shown in Section 5. Finally, conclusions are given in Section 6.

\section{Characteristics of Energy-Intensive Loads and Wind Power}

\subsection{Characteristics of Energy-Intensive Loads}

As most of the local energy-intensive loads in Gansu are electrolytic aluminum production loads, here we take electrolytic aluminum as an example to show the characteristics of energy-intensive loads. Electrolytic aluminum production takes cryolite-alumina as the raw material, and aluminum is obtained after an electrolysis process. Under normal circumstances, the electrical load of electrolytic aluminum is stable [6], and the regulation within a certain range only affects the quantity but not the quality of product nor the safety of the equipment. However, the impact resistance of electrolytic aluminum equipment is limited, so it is necessary to stabilize the production for a period of time after one regulation [21]. The regulation characteristics of electrolytic aluminum are shown in Figure 1.

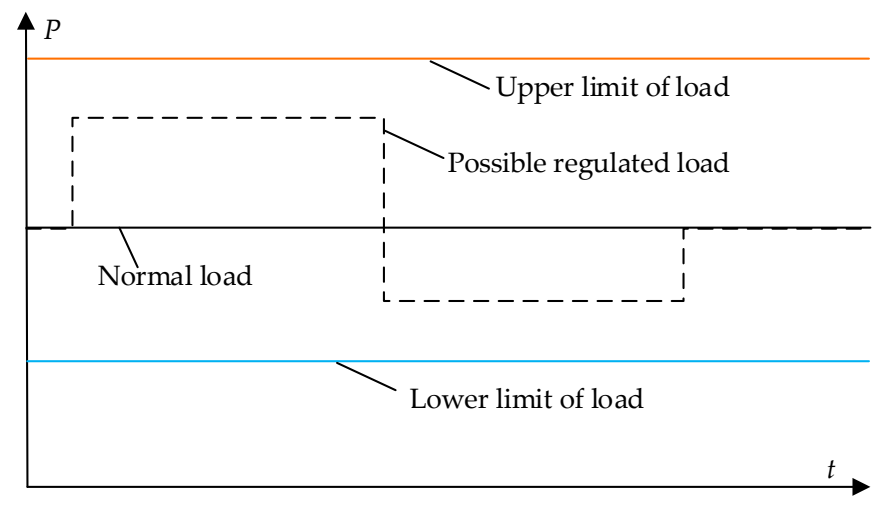

Figure 1. Regulation characteristics of electrolytic aluminum.

The mathematical formulation in this paper is based on discrete time representation and the overall control period (say one day) is split into $T$ intervals of equal duration $\Delta t$ (for example $15 \mathrm{~min}$ ). According to characteristics of electrolytic aluminum, corresponding control model is established as follows: 
(1) Limitations of upper and lower boundary power of load:

$$
P_{\mathrm{D} i, \min }^{t} \leq P_{\mathrm{D} i}^{t} \leq P_{\mathrm{D} i, \max }
$$

where, $i$ represents the $i$ th energy-intensive load; $t$ represents the $t$ th duration; $P_{\mathrm{D} i}^{t}$ is the power of energy-intensive load in $\mathrm{MW} ; P_{\mathrm{Di} \text {,min }}^{t}, P_{\mathrm{D} i \text {,max }}$ are respectively the technically allowed maximum and minimum power of the energy-intensive load in MW.

(2) Limitations of the minimum duration of stable operation:

$$
\begin{aligned}
& \sum_{t=\tau}^{\tau+T_{\text {compi }}-1} S_{\mathrm{p} i}(t) \leq 1 \\
& \forall \tau \in\left[1, T-T_{\text {compi }}+1\right] \\
& -S_{\mathrm{p} i}(t) M \leq P_{\mathrm{D} i}^{t}-P_{\mathrm{D} i}^{t-1} \leq S_{\mathrm{p} i}(t) M
\end{aligned}
$$

where, $S_{\mathrm{p} i}(t)$ is a state variable of energy-intensive load, $S_{\mathrm{p} i}(t) \in\{0,1\}$, When $S_{\mathrm{p} i}(t)=0$, the load power has to keep stable and regulation is not allowed, that is $P_{\mathrm{D} i}^{t}=P_{\mathrm{D} i}^{t-1}$, and when $S_{\mathrm{p} i}(t)=1$, a load regulation is allowed, that is $P_{\mathrm{D} i}^{t}$ can be different from $P_{\mathrm{D} i}^{t-1} ; T_{\text {comp } i}$ is the required minimum duration of stable operation of energy-intensive load; $M$ is a parameter introduced for model linearization in $\mathrm{MW}, M \geq P_{\mathrm{D} i, \max }-P_{\mathrm{D} i \text { min }}$.

(3) Limitations on the overall number of regulations:

$$
\sum_{t=1}^{T} S_{\mathrm{p} i}(t) \leq N_{i, \max }
$$

where, $N_{i, \max }$ is the maximum number of times of regulation of the energy-intensive load during the control period.

\subsection{Characteristics of Large-Scale Wind Power}

Influenced by various weather factors, wind power is characterized by fluctuation. The changes of large-scale wind power in Hexi region of Gansu Province during three consecutive days randomly selected from the year of 2016 are shown in Figure 2 (it has to be pointed out that data shown is the available wind power, it may be greater than the actual output of wind power considering the possible derating required by the grid operator). Obvious fluctuation of the wind power can be observed from Figure 2. According to 2016 statistics, the maximum change of wind power in Hexi in $1 \mathrm{~min}, 5 \mathrm{~min}$, $15 \mathrm{~min}$ are respectively $259 \mathrm{MW}, 609 \mathrm{MW}$ and $1457 \mathrm{MW}$, accounting for $2.5 \%, 5.9 \%$ and $14.1 \%$ of the installed capacity of wind power in Hexi [22].

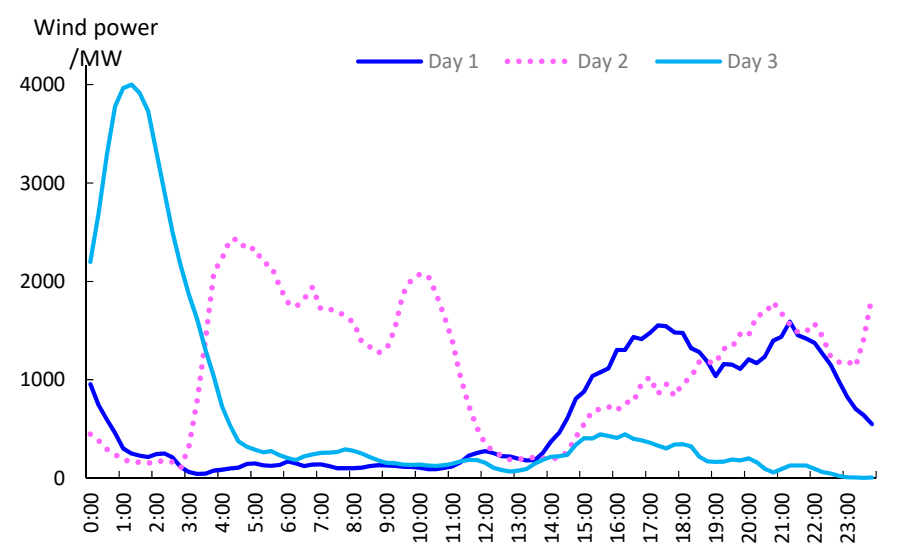

Figure 2. Profile of wind power in Hexi, Gansu. 


\section{Characteristic Mismatches between Energy-Intensive Loads and Wind Power and Ancillary Regulation of Coal-Fueled Units}

\subsection{Characteristic Mismatches of Energy-Intensive Loads and Wind Power}

The basic idea of promoting wind power consumption using energy-intensive loads is to increase the load when there is curtailed wind power that could not be consumed by the system in the conventional dispatching mode which doesn't include the demand side flexibility into regulation. A conventional dispatching scheme is where the discussion in this paper starts. The curtailed wind power referred in this paper is the part of available wind power that exceeds the generation plan given in the conventional dispatching scheme. A considerable amount of curtailed wind power could be consumed by regulating energy-intensive loads according to the curtailed wind power profile.

However, constrained by the minimum duration of stable operation, the regulated load curve is composed of multiple horizontal lines (see Figure 1) and the wind power appears to be an irregular fluctuating curve (see Figure 2). Thus energy-intensive load regulation cannot fully follow the curtailed wind power owing to characteristic mismatches. The schematic of curtailed wind power consumption using energy-intensive loads is shown in Figure 3. Note that curves in Figure 3 are qualitative curves without connection to Figures 1 and 2.

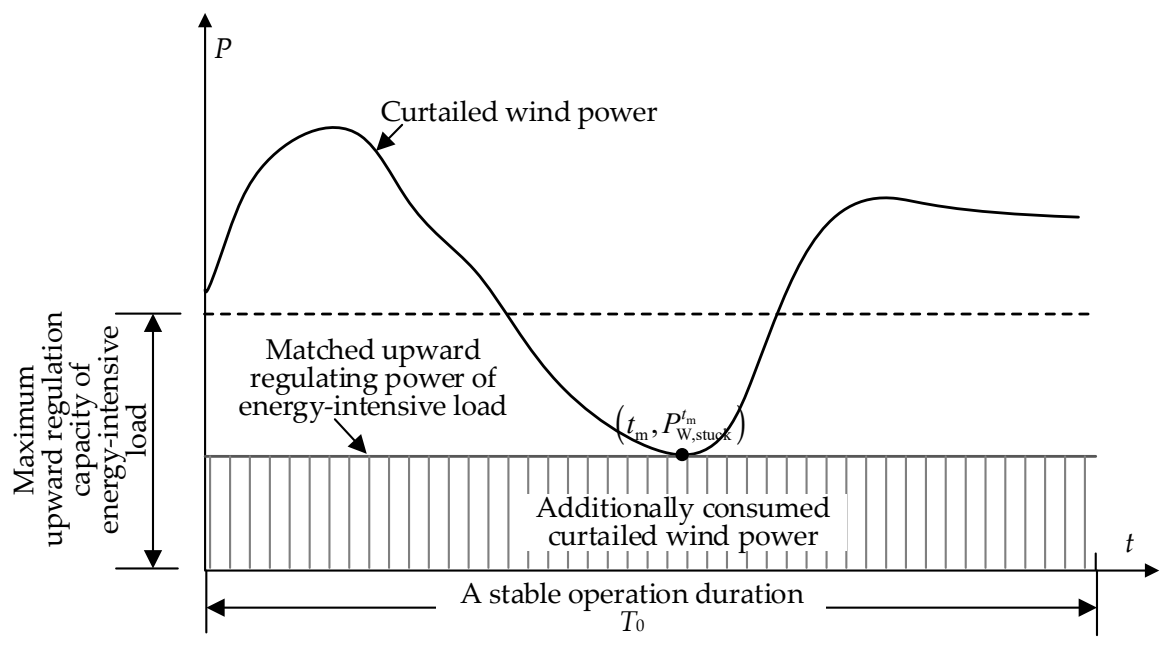

Figure 3. Curtailed wind power consumption with energy-intensive loads involved.

As we can see from Figure 3, during the stable operation duration $T_{0}$, the regulating load power has to be consistent. To keep the energy balance of the system, the regulating load power is matched to be equivalent to the minimum curtailed wind power during $T_{0}$. In this way, the curtailed wind power within the maximum upward regulation capacity of energy-intensive load is not completely consumed, and that leaves much to do to make better use of the regulation capacity to further promote the consumption of curtailed wind power.

Here, we define the utilization rate of energy-intensive loads' regulation capacity in the process of consuming the curtailed wind power $\eta_{T}$ to quantify the aforementioned phenomenon:

$$
\begin{gathered}
\eta_{T}=\frac{S}{S_{\max }} \\
S_{\max }=\sum_{t=1}^{T} \min \left\{P_{\mathrm{W}, \text { cgt } t}^{t}, \sum_{i=1}^{N_{\mathrm{D}}} P_{\mathrm{D} i, \text { upmax }}^{t}\right\} \Delta t \\
S=\sum_{t=1}^{T} \min \left\{P_{\mathrm{W}, \mathrm{cg} t}^{t}, \sum_{i=1}^{N_{\mathrm{D}}} P_{\mathrm{D} i, u p}^{t}\right\} \Delta t
\end{gathered}
$$




$$
\begin{aligned}
P_{\mathrm{D} i, \mathrm{upmax}}^{t} & =P_{\mathrm{D} i, \max }^{t}-P_{\mathrm{D} i, 0}^{t} \\
P_{\mathrm{D} i, \mathrm{up}}^{t} & =P_{\mathrm{D} i}^{t}-P_{\mathrm{D} i, 0}^{t}
\end{aligned}
$$

where, $S_{\max }$ is the maximum possible consumption of curtailed wind power with energy-intensive loads in MWh; $S$ is the actual consumption of curtailed wind power with energy-intensive loads in MWh; $P_{\mathrm{W}, \mathrm{cgt}}^{t}$ is the curtailed wind power in MW; $N_{\mathrm{D}}$ is the number of energy-intensive loads involved in the regulation; $P_{\mathrm{D} i, 0}^{t}$ is the original load power of energy-intensive load in $\mathrm{MW} ; P_{\mathrm{D} i \text {,max }}^{t} P_{\mathrm{D} i \text {, up }}^{t}$ are respectively the maximum upward regulating capacity and the actual upward regulating power of the energy-intensive load in MW.

\subsection{Further Reducing Curtailed Wind Power with Ancillary Regulation of Coal-Fueled Units}

As analyzed in Section 3.1, to maintain the energy balance of the power system, the upward regulating power of energy-intensive loads have to be equivalent to the minimum curtailed wind power during the stable operation duration. It is reasonable to come up with the idea of requiring ancillary regulation from coal-fueled units, which means to increase the output of coal-fueled units when the curtailed wind power is temporarily low and limits the utilization of energy-intensive loads' regulation capacity, the corresponding schematic is shown in Figure 4.

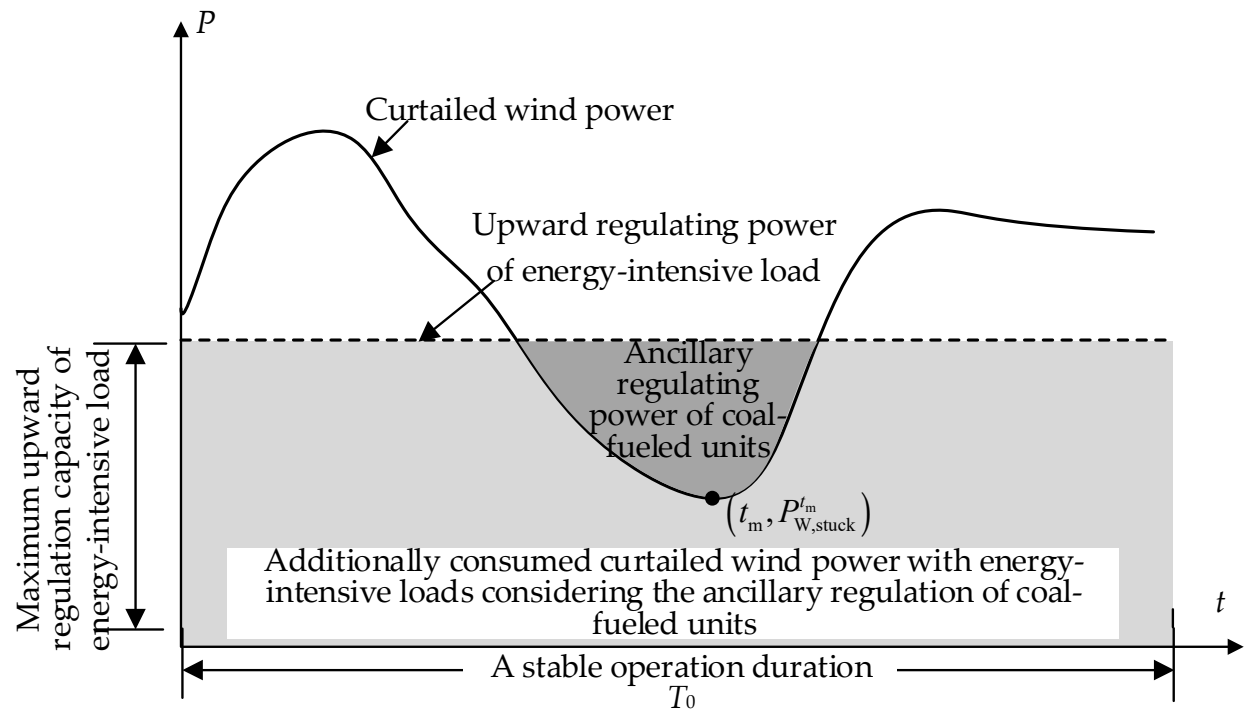

Figure 4. Curtailed wind power consumption with energy-intensive loads considering the ancillary regulation power of coal-fueled units.

It can be seen from Figure 4 that, with ancillary regulating power provided by coal-fueled units during the period when the curtailed wind power is relatively low, the upward regulating power of energy-intensive loads can be raised even to the maximum regulation capacity in the whole stable operation duration without damaging the energy balance of the power system. Comparing Figure 3 with Figure 4, it can be observed that the consumed curtailed wind power with energy-intensive loads significantly increases when taking the ancillary regulating power into consideration.

\section{Bi-Level Coordinative Model for Consuming Curtailed Wind Power with Energy-Intensive Loads Considering the Ancillary Regulation of Coal-Fueled Units}

Though the compensation mechanism is not what we focus in this paper, it is not difficult to get the point that the compensation for ancillary regulation would be part of the cost of consuming the curtailed wind power. So we intend to achieve the maximum consumption of the curtailed wind power with the minimum ancillary regulation. Thus a bi-level coordinative model is proposed. The first-level optimization aims to maximize the consumption of curtailed wind power and minimize 
the ancillary regulating energy. The second-level optimization is to allocate the regulating power among the involved coal-fueled units with minimum generation cost.

\subsection{First-Level Optimization Model}

(1) Objective

The objectives of the first-level optimization are set as follows:

Objective A:

$$
\max f_{1 \mathrm{~A}}=\sum_{t=1}^{T} P_{W c, c g t}^{t} \Delta t
$$

Objective B:

$$
\min f_{1 \mathrm{~B}}=\sum_{t=1}^{T} P_{\mathrm{G}, a u x}^{t} \Delta t
$$

where, $f_{1 \mathrm{~A}}$ is the consumed curtailed wind energy during the control period in MWh; $f_{1 \mathrm{~B}}$ is the ancillary regulating energy provided by the coal-fueled units during the control period in $\mathrm{MWh} ; P_{\mathrm{Wc}, \mathrm{cgt}}^{t}$ is the consumed curtailed wind power in MW; $P_{\mathrm{G}, \text { aux }}^{t}$ is the total ancillary power of the coal-fueled units in MW. Let $T=96, \Delta t=15 \mathrm{~min}$ and the control period is one day (24h) in this paper.

In order to facilitate the model solving, objective A \& B are combined as a single objective through weight coefficient setting as follows:

$$
\max f_{1}=\frac{\varepsilon_{\mathrm{A}} f_{1 \mathrm{~A}}+\varepsilon_{\mathrm{B}}\left(-f_{1 \mathrm{~B}}\right)}{\varepsilon_{\mathrm{A}}+\varepsilon_{\mathrm{B}}}
$$

where, $\frac{\varepsilon_{\mathrm{A}}}{\varepsilon_{\mathrm{A}}+\varepsilon_{\mathrm{B}}}$ and $\frac{\varepsilon_{\mathrm{B}}}{\varepsilon_{\mathrm{A}}+\varepsilon_{\mathrm{B}}}$ are respectively the weight coefficients of the two objectives. As objective A is the priority issue to be addressed, that is, the objective $B$ needs to be implemented on the basis of achieving objective $\mathrm{A}$, so $\varepsilon_{\mathrm{A}} \gg \varepsilon_{\mathrm{B}}$ should be guaranteed when setting the weight coefficients.

(2) Constraints:

$$
\begin{gathered}
P_{\mathrm{D} i}^{t}=P_{\mathrm{D} i, 0}^{t}+P_{\mathrm{D} i, \mathrm{up}}^{t} \\
P_{\mathrm{Wc}, \mathrm{cgt}}^{t}+P_{\mathrm{G}, \text { aux }}^{t}=\sum_{i=1}^{N_{\mathrm{D}}} P_{\mathrm{D} i, \text { up }}^{t} \\
P_{\mathrm{Wc}, \mathrm{cgt}}^{t} \leq P_{\mathrm{W}, \mathrm{cgt}}^{t} \\
P_{\mathrm{G}, \text { org }}^{t}+P_{\mathrm{G}, \text { aux }}^{t} \leq P_{\mathrm{G}, \text { max }}^{t} \\
P_{\mathrm{G}, \text { aux }}^{t} \geq 0 \\
\left|\left(P_{\mathrm{G}, \text { org }}^{t}+P_{\mathrm{G}, \text { aux }}^{t}\right)-\left(P_{\mathrm{G}, \text { org }}^{t-1}+P_{\mathrm{G}, \text { aux }}^{t-1}\right)\right| \leq R_{\mathrm{G}, \max }^{t}
\end{gathered}
$$

where, $P_{\mathrm{G}, \text { org }}^{t}$ and $P_{\mathrm{G}, \max }^{t}$ are respectively the total original generation schedule and maximum total output of the coal-fueled units in $\mathrm{MW} ; R_{\mathrm{G}, \max }^{t}$ is the total maximum ramping power of the coal-fueled units in MW.

Besides, the energy-intensive loads related control constraints which also need to be included in the model are as shown in Equations (1)-(4). 


\subsection{Second-Level Optimization Model}

(1) Objective

The second-level optimization is to be provide the demanded ancillary regulation with minimum generation cost, the objective can be expressed as:

$$
\min f_{2}=\sum_{j=1}^{N_{\mathrm{G}}} C_{j}
$$

where, $f_{2}$ is the generation cost of the ancillary regulation in $\$ ; N_{G}$ is the number of the coal-fueled units involved, and $C_{j}$ is the ancillary regulation cost of coal-fueled unit $j$ in $\$$ [23]:

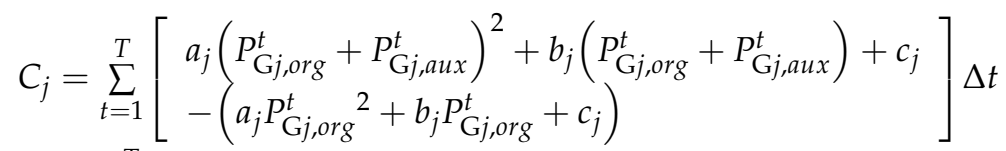

$$
\begin{aligned}
& =\sum_{t=1}^{T}\left[a_{j} P_{\mathrm{G} j, \text { aux }}^{t}{ }^{2}+\left(2 a_{j} P_{\mathrm{G} j, \text { org }}^{t}+b_{j}\right) \times P_{\mathrm{G} j, a u x}^{t}\right] \Delta t
\end{aligned}
$$

where, $P_{\mathrm{G} j \text {,aux }}^{t}$ is the ancillary regulating power of coal-fueled unit $j$ in $\mathrm{MW} ; P_{\mathrm{G} j \text {,org }}^{t}$ is the original generation schedule of coal-fueled unit $j$ in $\mathrm{MW} ; a_{j} b_{j} c_{j}$ are the operating cost parameters [23] of coal-fueled unit $j$ respectively in $\$ /(M W)^{2} h, \$ / M W h$ and $\$ / h$.

(2) Constraints:

$$
\begin{gathered}
\sum_{j=1}^{N_{\mathrm{G}}} P_{\mathrm{G} j, \mathrm{aux}}^{t}=P_{\mathrm{G}, \text { aux }, \text { opt }}^{t} \\
P_{\mathrm{G} j, \text { org }}^{t}+P_{\mathrm{G} j, \mathrm{aux}}^{t} \leq P_{\mathrm{G} j, \mathrm{max}}^{t} \\
P_{\mathrm{G} j, \text { aux }}^{t} \geq 0 \\
\left|\left(P_{\mathrm{G} j, \text { org }}^{t}+P_{\mathrm{G} j, \text { aux }}^{t}\right)-\left(P_{\mathrm{G} j, \text { org }}^{t-1}+P_{\mathrm{G} j, \text { aux }}^{t-1}\right)\right| \leq R_{\mathrm{G} j, \text { max }}^{t}
\end{gathered}
$$

where, $P_{\mathrm{G}, \text { aux }, \mathrm{opt}}^{t}$ is demanded ancillary power calculated by the first-level optimization in MW; $P_{\mathrm{G} j \text {,max }}^{t}$ is the maximum output of coal-fueled unit $j$ in $\mathrm{MW} ; R_{\mathrm{G} j, \max }^{t}$ is the maximum ramping power of coal-fueled unit $j$ in MW.

Equation (21) is the boundary condition to be satisfied for the second-level optimization given by the first-level optimization. The proposed model can be solved with Mosek in MATLAB.

\section{Case Analysis}

In this section, a simulation on a modified system based on the Hexi District power grid in Gansu, China, is used to show the performance of coordinative scheduling. The simplified diagram of the target system is as shown in Figure 5. The original generation schedule and other parameters of the coal-fueled units involved to provide ancillary regulation are respectively shown in Figure 6 and Table 1. The parameters of energy-intensive loads involved in the consumption of curtailed wind power are shown in Table 2. The curtailed wind power is shown in Figure 7. 


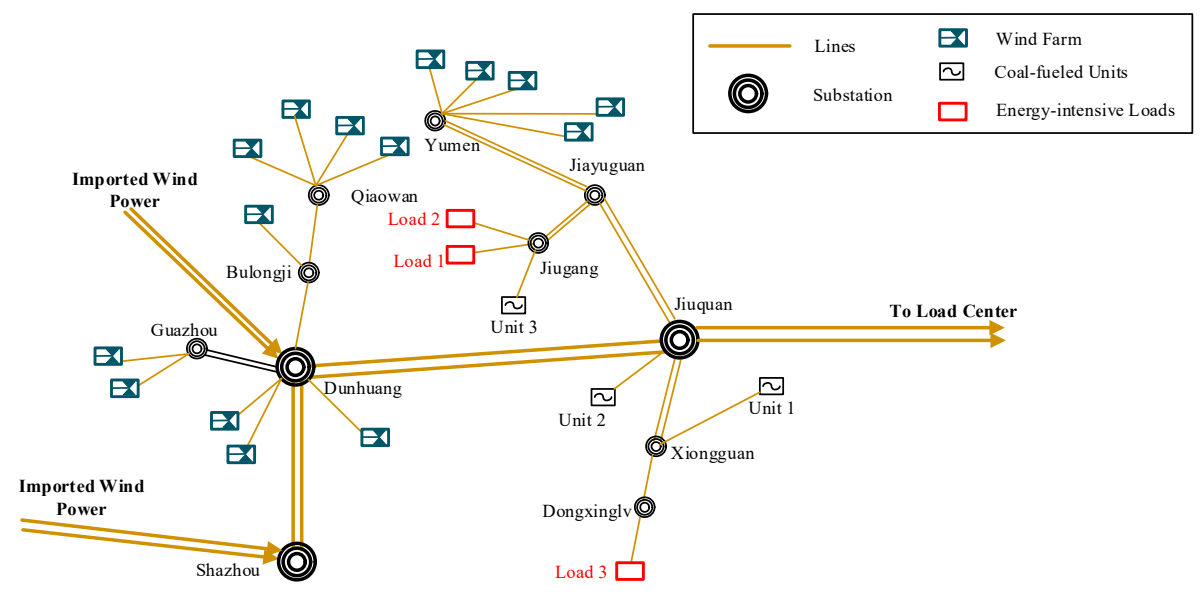

Figure 5. The simplified diagram of the target system.

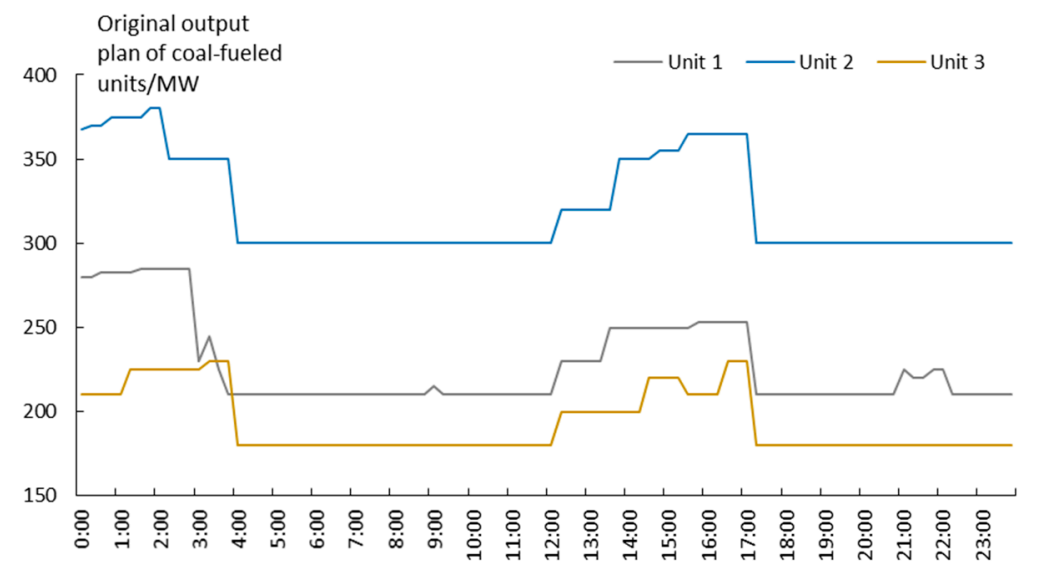

Figure 6. Original generation schedule of coal-fueled units.

Table 1. Parameters of coal-fueled units.

\begin{tabular}{|c|c|c|c|c|c|}
\hline Unit & $\begin{array}{c}\text { Lower Limit of } \\
\text { Output/MW }\end{array}$ & $\begin{array}{l}\text { Upper Limit of } \\
\text { Output/MW }\end{array}$ & $a_{j} /\left(\$ /(M W)^{2} h\right)$ & $\mathrm{b}_{\mathrm{j}} /(\$ / \mathrm{MWh})$ & $\begin{array}{c}\text { Maximum } \\
\text { Ramping } \\
\text { Rate/(MW/min) }\end{array}$ \\
\hline Unit 1 & 210 & 350 & 0.051 & 50 & 6 \\
\hline Unit 2 & 300 & 600 & 0.045 & 41 & 10 \\
\hline Unit 3 & 180 & 300 & 0.108 & 50 & 5 \\
\hline
\end{tabular}

Table 2. Parameters of energy-intensive loads.

\begin{tabular}{cccccccc}
\hline $\begin{array}{c}\text { Energy-Intensive } \\
\text { Load }\end{array}$ & $\begin{array}{c}\text { Rated } \\
\text { Power/MW }\end{array}$ & $\begin{array}{c}\text { Original Load } \\
\text { Power/MW }\end{array}$ & $\begin{array}{c}\text { Minimum Load } \\
\text { Power/MW }\end{array}$ & $\begin{array}{c}\text { Maximum Load } \\
\text { Power/MW }\end{array}$ & $\begin{array}{c}\text { Maximum } \\
\text { Upward } \\
\text { Regulation } \\
\text { Capacity/MW }\end{array}$ & $\begin{array}{c}\text { Minimum } \\
\text { Duration of } \\
\text { Stable } \\
\text { Operation/h }\end{array}$ & $\begin{array}{c}\text { Maximum } \\
\text { Number of } \\
\text { Times of } \\
\text { Regulation Per } \\
\text { Day }\end{array}$ \\
\hline Load 1 & 700 & 700 & 630 & 770 & 70 & 4 \\
Load 2 & 1400 & 1400 & 1260 & 1540 & 140 & 4 \\
Load 3 & 500 & 500 & 425 & 575 & 75 & 4 \\
\hline
\end{tabular}




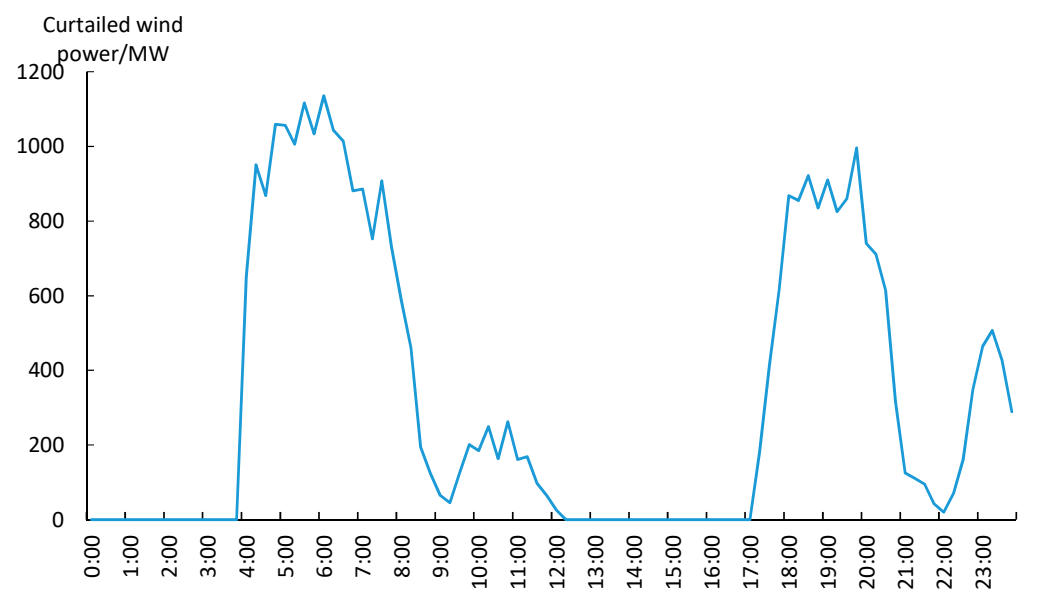

Figure 7. Curtailed wind power in the conventional dispatching mode.

\subsection{Analysis of the Results of First-Level Optimization}

We compare the consumptions of curtailed wind power in the following two modes:

Mode 1: Coordinating the regulation capacity of energy-intensive loads and curtailed wind power considering the ancillary regulation of coal-fueled units (employing the coordinative model proposed in this paper, see Equation (1)-(4) and (12)-(18)).

Mode 2: Coordinating the regulation capacity of energy-intensive loads and curtailed wind power without considering the ancillary regulation of coal-fueled units (let $P_{\mathrm{G}, \text { aux }}^{t}=0$ in the proposed model).

Coordination results are shown in Figure 8 and Table 3. The detailed regulating curves of involved energy-intensive loads in different modes are shown in Figures A1 and A2 in the Appendix.

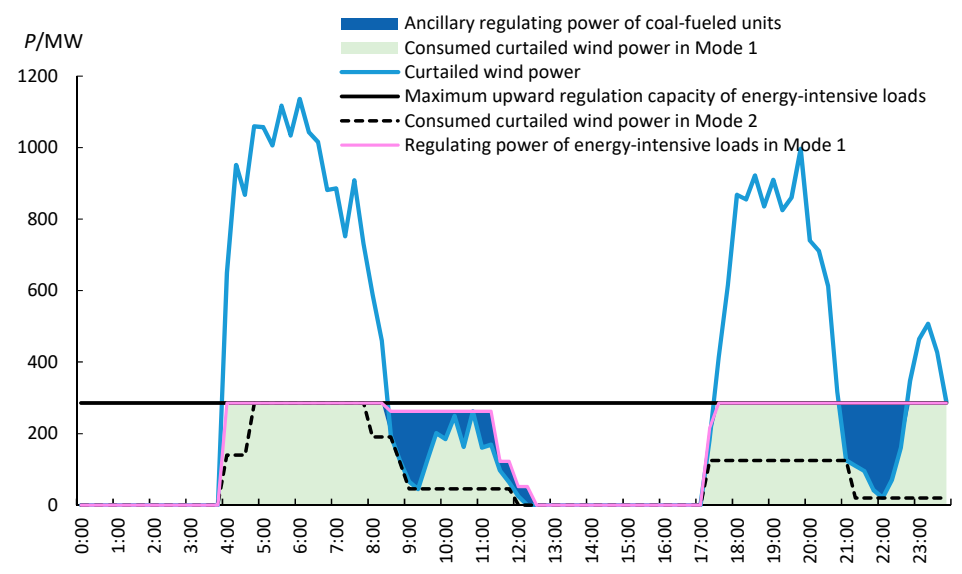

Figure 8. Consumptions of curtailed wind power in different modes.

Table 3. Comparison of control results in different modes.

\begin{tabular}{cccc}
\hline Mode & $\begin{array}{c}\text { Consumption of } \\
\text { Curtailed Wind } \\
\text { Power/MWh }\end{array}$ & $\begin{array}{c}\text { Ancillary Regulating } \\
\text { Energy of Coal-Fueled } \\
\text { Units/MWh }\end{array}$ & $\begin{array}{c}\text { Utilization Rate of } \\
\text { Energy-Intensive Loads' } \\
\text { Regulation Capacity }\end{array}$ \\
\hline 1 & 3369.25 & 692.50 & $100 \%$ \\
2 & 1893.75 & $/$ & $56.2 \%$ \\
\hline
\end{tabular}

It can be seen from Figure 7 that a great amount of the curtailed wind power can be consumed by simply increasing the energy-intensive loads without the ancillary regulation of coal-fueled units in Mode 2. However, during 4:00 4:30, 8:00 12:00, 17:15 24:00, the capacity of energy-intensive load is not used up, nor is the curtailed wind power all consumed, which result in the utilization rate of 
energy-intensive loads' regulation capacity to be only $56.2 \%$. This is because the profile of regulating power of energy-intensive loads is composed of multi horizontal lines, which determines that the regulating power for an interval is not only limited by the regulation capacity and the curtailed wind power at this interval, but also limited by the conditions of adjacent intervals. It could be observed in Figure 7 that regulating power of energy-intensive loads during 9:00 11:45 is all limited by the curtailed wind power at 9:15 in Mode 2, leaving the regulation capacity insufficiently utilized. By levelling out the trough in wind power with ancillary regulation provided by coal-fueled units in Mode 1 , the characteristic mismatches between wind power and energy-intensive loads are alleviated, and it can free the regulation of energy-intensive loads from the limitation of the minimum curtailed wind power in a certain duration. Thus the utilization rate of energy-intensive loads' regulation capacity is increased to $100 \%$ in Mode 1. Accordingly, energy-intensive loads consumes 1,475.50MWh of curtailed wind power more in Mode 1 than in Mode 2, which accounts for $77.91 \%$ of the consumption of curtailed wind power in Mode 2.

In conclusion, involving the energy-intensive loads in consuming the wind power can raise the wind power consumption to an extent. Even better, the ancillary regulation of coal-fueled units can help to alleviate the characteristics mismatches between the wind power and energy-intensive loads and the proposed coordination method can make the most of the regulation capacity of energy-intensive loads, thus to further increase the consumption of wind power consumption significantly.

\subsection{Analysis of the Results of Second-Level Optimization}

The second-level optimization is to economically allocate the needed ancillary regulation power among the coal-fueled units, the corresponding allocation can be referred as Allocation 1 . There is another allocation scheme, in which the allocated ancillary regulation power is in proportion to the available capacity of the units, and the corresponding allocation can be referred as Allocation 2 . Comparisons of the two allocations are shown in Table 4.

Table 4. Comparisons of different allocations.

\begin{tabular}{llcccc}
\hline & Allocation & Unit 1 & Unit 2 & Unit 3 & Total \\
\hline \multirow{2}{*}{ Allocation 1 } & Ancillary regulating energy/MWh & 158.62 & 532.93 & 0.95 & 692.50 \\
& Cost of the ancillary regulation/\$ & $11,902.80$ & $38,972.00$ & 84.60 & $50,959.40$ \\
\hline \multirow{2}{*}{ Allocation 2 } & Ancillary regulating energy/MWh & 167.97 & 374.89 & 149.64 & 692.50 \\
& Cost of the ancillary regulation/\$ & $12,428.30$ & $26,986.80$ & $13,894.60$ & $53,309.70$ \\
\hline
\end{tabular}

It can be seen from Table 4 that in Allocation 1, the ancillary regulation power is mainly allocated to the unit 2 and the unit 1 which have better economic performances. Compared with Allocation 2, the ancillary regulation cost of Allocation 1 can be reduced by $\$ 2350.30$. The proposed method can allocate the regulating energy economically with the second-level optimization. It must be pointed out here that since the ancillary regulation cost is related to the original generation schedule of the unit (see Equation (20)), the economic performance of the unit's ancillary regulation varies with original generation schedule.

In the case analyzed above, the wind power consumption is increased by $1475.50 \mathrm{MWh}$ with 692.50 MWh ancillary regulating energy. Let the tariff of wind power be $67.16 \$ / \mathrm{MWh}$, then the economic benefit brought by the ancillary regulation can be calculated and a comparison of the brought benefit and cost of the ancillary regulation can be made as shown in Table 5 .

Table 5. Cost and benefit of the ancillary regulation.

\begin{tabular}{cc}
\hline Cost of the Ancillary Regulation/\$ & Economic Benefit Brought by Ancillary Regulation/\$ \\
\hline $50,959.40$ & $99,094.58$ \\
\hline
\end{tabular}


It can be seen from Table 5 that the economic benefits brought by ancillary regulation far outweighs the cost of ancillary regulation. The schedule is economically practical in some way.

\subsection{Practical Application}

The proposed method has been applied in a project in Hexi District (Gansu, Western China), which is intended to promote the consumption of renewable energies by coordinating the system and local energy-intensive loads. Hexi District is where renewable energy generation system of Jiuquan is located. The installed capacity of the renewable power included in the project is 10,840 MW, and the installed capacity of involved energy-intensive loads is $2900 \mathrm{MW}$. The involved loads mainly comprise the load of electrolytic aluminum production at the Enterprise of Dongxing Aluminum in the City of Jiayuguan. The coal-fueled units of Jiugang, with an overall capacity of approximately $3000 \mathrm{MW}$ in the City of Jiayuguan are also involved in the project. The load regulation of electrolytic aluminum in the project is realized by changing the production current. The load power ranges within $100-105 \%$ of rated power during the regulation. According to the operation data during September to December, 2016, the coordination increases the wind power consumption by 22,258 MWh. Based on what has been implemented, we expect to make greater changes by including more loads into the project to further promote the consumption of renewable energy in China.

\section{Conclusions and Future Work}

The flexibility of energy-intensive loads are believed to be beneficial for improving the performance of the power grid. The coordination between the system and the energy-intensive loads is even more meaningful in systems with high wind power penetration rates or other intermittent and uncertain energies, as the energy-intensive loads can be regulated according to the availability of the wind power, which can help reduce the curtailed wind power.

To make the load-source coordination practical in China, many application limitations were considered in the paper. Besides, the technical operational requirements were comprehensively considered and modeled, including the minimal duration of stable operation, which was neglected by existing literatures. To alleviate characteristic mismatches between the wind power and energy-intensive loads, which limited the consumption of curtailed wind power with energy-intensive loads, a scheme of providing ancillary regulating power by the coal-fueled units was put forward to make better use of the capability of energy-intensive loads to further consume the curtailed wind power. And the proposed coordinative method showed great advantage in promoting the wind power consumption.

In the future, the quantification of contributions of the involved energy-intensive loads and coal-fueled units in promoting wind power consumption needs to be explored, as it is important in constructing a reasonable compensation mechanism.

Author Contributions: Investigation, D.Z.; Methodology, D.Z. and W.L.; Supervision, W.L.; Writing-original draft, D.Z.; Writing—review \& editing, Y.H. and W.W.

Funding: The authors gratefully acknowledge the support of the National Key Technologies R\&D Program (No. 2015BAA01B04), Science and Technology Project of State Grid Corporation of China(52272216002D), Science and Technology Project of State Grid Corporation of Gansu Province (No. SGGSKY00JNJS1700149).

Conflicts of Interest: The authors declare no conflict of interest. 


\section{Appendix A}

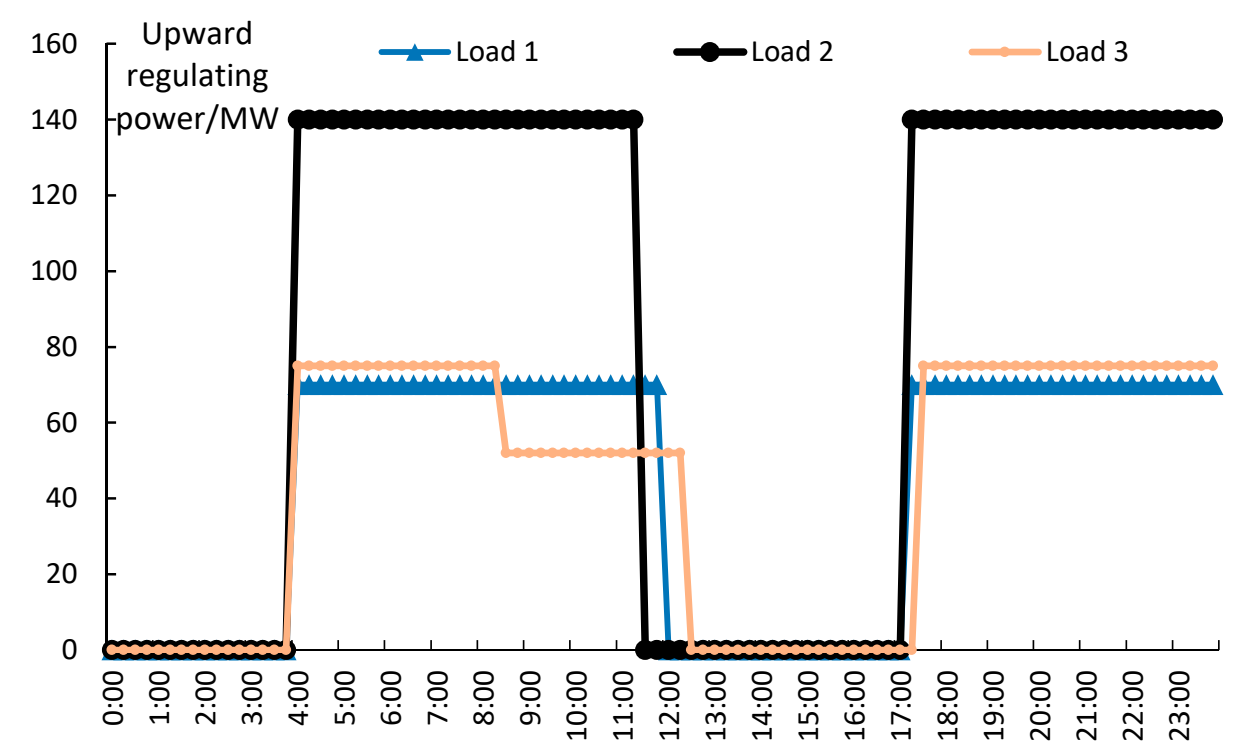

Figure A1. Regulation of energy-intensive loads in Mode 1.

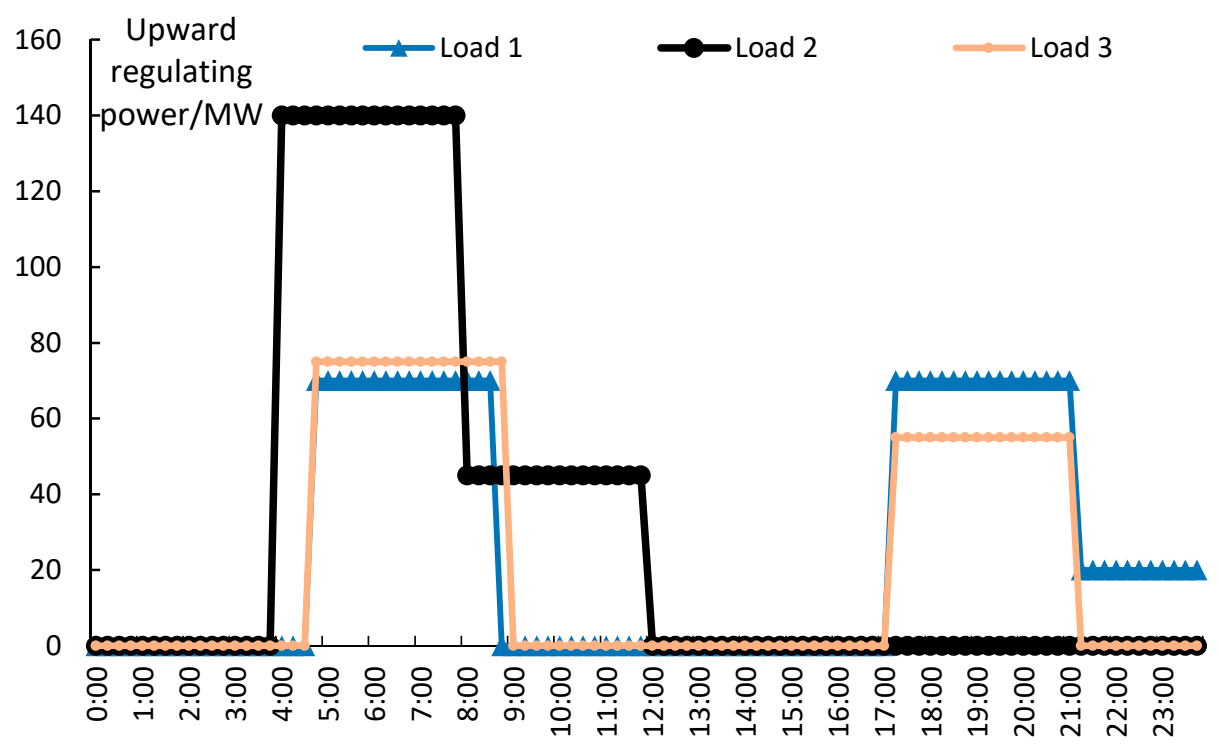

Figure A2. Regulation of energy-intensive loads in Mode 2.

\section{References}

1. China Electricity Council. Annual Report of Wind Power Development in China 2017; China Electricity Council: Beijing, China, February 2018. (In Chinese)

2. Bitaraf, H.; Rahman, S. Reducing Curtailed Wind Energy Through Energy Storage and Demand Response. IEEE Trans. Power Syst. 2018, 9, 228-236. [CrossRef]

3. Paulus, M.; Borggrefe, F. The Potential of Demand-side Management in Energy-intensive Industries for Electricity Markets in Germany. Appl. Energy 2011, 88, 432-441. [CrossRef]

4. Samad, T.; Kiliccote, S. Smart Grid Technologies and Applications for the Industrial Sector. Comput. Chem. Eng. 2012, 47, 76-84. [CrossRef]

5. Pelzer, A.; Richter, M.; Lombardi, P.A.; Komarnicki, P. Energy Intensive Industry as the Backbone for Demand Side Flexibility. In Proceedings of the International ETG Congress, Bonn, Germany, 28-29 November 2017; pp. 1-6. 
6. Todd, D.; Caufield, M.; Helms, B.; Starke, M.; Kirby, B.; Kueck, J. Providing Reliability Services through Demand Response: A Preliminary Evaluation of the Demand Response Capabilities of Alcoa Inc.; Technical Report for Federal Energy Regulatory Commission; Federal Energy Regulatory Commission: Washington, DC, USA, February 2009.

7. Groenewald, H.; Vosloo, J.C. Cost-benefit to the Cement Industry by Shifting Evening Load to Off-peak Periods. In Proceedings of the 9th Industrial and Commercial Use of Energy Conference, Stellenbosch, South Africa, 15-16 August 2012.

8. Drovtar, I.; Uuemaa, P.; Rosin, A.; Kilter, J.; Valtin, J. Using Demand Side Management in Energy-intensive Industries for Providing Balancing Power-The Estonian Case Study. In Proceedings of the 2013 IEEE Power \& Energy Society General Meeting, Vancouver, BC, Canada, 21-25 July 2013; pp. 1-5.

9. Ramin, D.; Spinelli, S.; Brusaferri, A. Demand-side Management via Optimal Production Scheduling in Power-intensive Industries: The Case of Metal Casting Process. Appl. Energy 2018, 225, 622-636. [CrossRef]

10. Babu, C.A.; Ashok, S. Peak Load Management in Electrolytic Process Industries. IEEE Trans. Power Syst. 2018, 23, 339-405. [CrossRef]

11. Zhang, X.; Hug, G.; Kolter, Z.; Harjunkoski, I. Computational Approaches for Efficient Scheduling of Steel Plants as Demand Response Resource. In Proceedings of the 2016 Power Systems Computation Conference (PSCC), Genoa, Italy, 20-24 June 2016.

12. Kwon, S.; Ntaimo, L.; Gautam, N. Optimal Day-Ahead Power Procurement with Renewable Energy and Demand Response. IEEE Trans. Power Syst. 2017, 32, 3924-3933. [CrossRef]

13. Varfolomejeva, R.; Gavrilovs, A.; Iljina, I. The Regulation Possibility of Energy-intensive Enterprises according to the Market Price Change. In Proceedings of the 2017 IEEE International Conference on Environment and Electrical Engineering and 2017 IEEE Industrial and Commercial Power Systems Europe (EEEIC/I\&CPS Europe), Milan, Italy, 6-9 June 2017.

14. Voropai, N.; Styczynski, Z.; Komarnicki, P.; Stepanov, V.; Suslov, K.; Stashkevich, E. Energy-intensive Manufacturing Enterprises as Active Players in Demand Side Management System. In Proceedings of the 2016 IEEE PES Innovative Smart Grid Technologies Conference Europe (ISGT-Europe), Ljubljana, Slovenia, 9-12 October 2016.

15. Ashok, S. Peak-load Management in Steel Plants. Appl. Energy 2006, 83, 413-424. [CrossRef]

16. Ashok, S.; Banerjee, R. Load-management Applications for the Industrial Sector. Appl. Energy 2000, 66, 105-111. [CrossRef]

17. Bao, Y.; Xu, J.; Liao, S.; Sun, Y.; Li, X.; Jiang, Y.; Ke, D.; Yang, J.; Peng, X. Field Verification of Frequency Control by Energy-Intensive Loads for Isolated Power Systems with High Penetration of Wind Power. IEEE Trans. Power Syst. 2018, 33, 6098-6108. [CrossRef]

18. Xu, J.; Liao, S.; Sun, Y.; Ma, X.Y.; Gao, W.; Li, X.; Gu, J.; Dong, J.; Zhou, M. An Isolated Industrial Power System Driven by Wind-Coal Power for Aluminum Productions: A Case Study of Frequency Control. IEEE Trans. Power Syst. 2015, 30, 471-483. [CrossRef]

19. Liao, S.; Xu, J.; Sun, Y.; Bao, Y.; Tang, B. Control of Energy-intensive Load for Power Smoothing in Wind Power Plants. IEEE Trans. Power Syst. 2018, 33, 6142-6154. [CrossRef]

20. Chen, R.; Sun, H.; Guo, Q.; Jin, H.; Wu, W.; Zhang, B. Profit-seeking Energy-intensive Enterprises Participating in Power System Scheduling: Model and Mechanism. Appl. Energy 2015, 158, $263-274$. [CrossRef]

21. Momber, I.; Wogrin, S.; Gomez, T. An MPEC for Electricity Retail Alternatives of Plug-in Electric Vehicle (PEV) Aggregators. In Proceedings of the 2014 Power Systems Computation Conference, Wroclaw, Poland, 18-22 August 2014.

22. Zhu, D.; Liu, W.; Xia, P.; Wang, W.; Liang, C. Load-source Coordinated Dispatch Method for Promoting Wind Power Accommodation Based on Rolling Optimization of Energy and Power. Autom. Electron. Power Syst. 2018, 42, 80-85.

23. Nanda, J.; Hari, L.; Kothari, M.L. Economic Emission Load Dispatch with Line Flow Constraints Suing a Classical Technique. IEE Proc. Gener. Transm. Distrib. 1994, 141, 1-10. [CrossRef]

(C) 2018 by the authors. Licensee MDPI, Basel, Switzerland. This article is an open access article distributed under the terms and conditions of the Creative Commons Attribution (CC BY) license (http:/ / creativecommons.org/licenses/by/4.0/). 